\title{
Perioperative Anesthetic Management for Surgical Repair of an Adult with Supracardiac Total Anomalous Pulmonary Venous Communication and Pulmonary Hypertension- Case Report and Mini Review
}

\author{
Vishnu Datt ${ }^{1}$, Rachna Wadhwa ${ }^{1}$, Manish Kumar ${ }^{1}$, Varun Sharma ${ }^{1}$, Ripon Chaudhary ${ }^{1}$, \\ Sanjula Virmani ${ }^{1}$
}

\section{Abstract}

The total anomalous pulmonary venous communication (TAPVC) is a rare cyanotic congenital cardiac defect accounting for $1.5-3 \%$ of the congenital heart disease, in which pulmonary venous (PV) blood drains directly into the right side of the heart or into the systemic veins. Neonates with obstructive TAPVC may present with cyanosis, metabolic acidosis, respiratory failure, and shock. A subset of patients with unobstructed TAPVC may remain symptoms free and attain adulthood, or present with pulmonary congestion, pulmonary arterial hypertension $(\mathrm{PAH})$. The anesthetic management of either obstructed TAPVC or unobstructed with $\mathrm{PAH}$ can be quite challenging. The described patient is a 23-year-old male who presented with self - limiting single episode of chest pain, palpitations and dyspnea, diagnosed as supracardiac unobstructed TAPVC with ostium secundum atrial septal defect (OS-ASD) and PAH, who underwent successful intracardiac repair under cardiopulmonary bypass (CPB). The protocol for the cardiac surgery during the COVID-19 pandemic for perioperative considerations and triage recommendations was strictly followed to reduce the risk of exposure to patients and healthcare workers. The objective of this case report and review is to recognize the spectrum of various clinical presentations in TAPVC, and to describe the diagnosis and perioperative management ofTAPVC.

Keywords: Adult Supra cardiac TAPVC, Unobstructed, PAH, Cardiopulmonary bypass, Corrective surgery, Balanced general anesthesia

\section{Introduction}

TAPVC is a rare form of cyanotic congenital cardiac anomaly accounting for $1 \%$ to $3 \%$ of congenital heart disease cases [1]. It's prevalence ranges from 0.6 to 1.2 per 10,000 live births $[2,3]$. TAPVC can be classified based on the level of pulmonary venous drainage or physiologic effects. Anatomic variants include supracardiac (45\%), cardiac $(25 \%)$, infracardiac $(20 \%)$, and mixed $(10 \%)$, while physiologic consequences include obstructive or non-obstructive venous drainage [4]. When obstructed at birth, the affected infants present with severe cyanosis, metabolic acidosis, low cardiac output and poor tissue perfusion unresponsive to standard resuscitation with prostaglandins and may require ventilatory and inotropic support or even emergency preoperative extracorporeal membrane oxygenation (ECMO). In contrast, the unobstructed TAPVC imposes a volume load on the right heart resulting in right atrial (RA) and right ventricular (RV) dilation and may lead to development of irreversible $\mathrm{PAH}[4,5]$. Some patients with adequate shunt at atrial level can remain asymptomatic and survive until adulthood. In the present case report the authors have described the successful perioperative management of cardiac correction of adult unobstructed supracardiac TAPVC with PAH.

\section{Case Report}

The patient, a previously healthy 23 -year-old male, presented with single episode of sudden onset chest pain associated with palpitations and bluish discoloration of fingertips and lips, along with dyspnea one month back, that resolved spontaneously after two hours. On examination, patient had mildly cyanosed fingertips, $\mathrm{SpO}_{2}$ of $93 \%$ on room air measured in upper limb, HR $86 \mathrm{bpm}$ and BP 106/72 mmHg. The systolic ejection murmur of grade $3 / 6$ was present at the upper left sternal border. His hematological and biochemical values were normal. Chest X-ray revealed mild cardiomegaly, prominent pulmonary vascular markings, and widening of superior mediastinum with the characteristic snowman or "figure of 8" appearance of Supracardiac TAPVC (Fig. 1). Transthoracic echocardiography revealed a supra-cardiac TAPVC with pulmonary venous confluence (PVC) connecting to the left innominate vein and draining into superior vena cava(SVC) (size $26.9 \mathrm{~mm}$ ), OS-ASD with right to left shunt, dilated right atrium (RA) and right ventricle (RV), left atrium (LA) size $2.4 \mathrm{~cm}$, left ventricular internal diameter in diastole (LVIDD) $4.4 \mathrm{~cm}$, left ventricular internal diameter in systole (LVIDS) $2.4 \mathrm{~cm}$, and LV ejection fraction of $60 \%$. The RV systolic pressure of 56 $\mathrm{mmHg}$. MRI confirmed the findings of echocardiography and thus

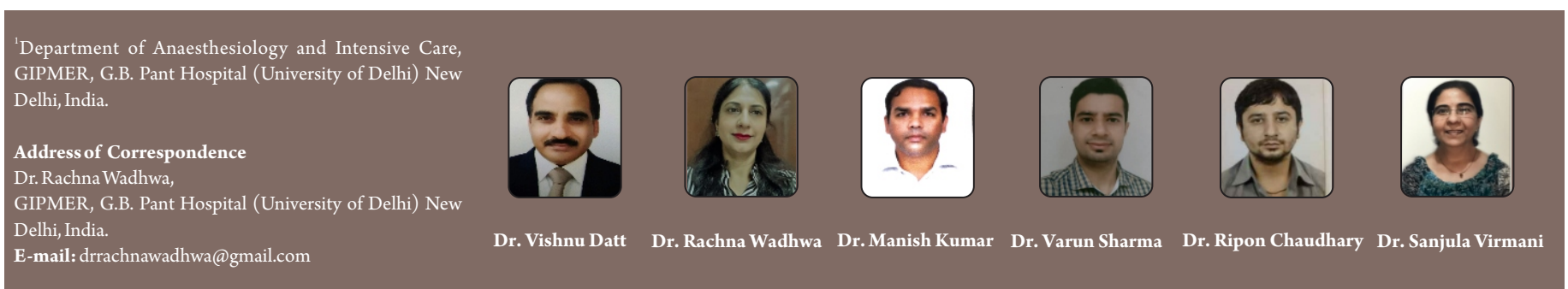

Submitted: 10/3/2021; Reviewed: 2/5/2021; Accepted: 17/8/2021; Published: 10/9/2021

$$
\text { DOI: 10.13107/jaccr.2021.v07i03.185 }
$$

This is an Open Access journal, and articles are distributed under the terms of the Creative Commons Attribution Non-Commercial-Share Alike 4.0 License (http://creativecommons.org/licenses/by-nc-sa/4.0) which allows others to remix, tweak, and build upon the work non-commercially as long as appropriate credit is given and the new creation are licensed under the identical terms. 


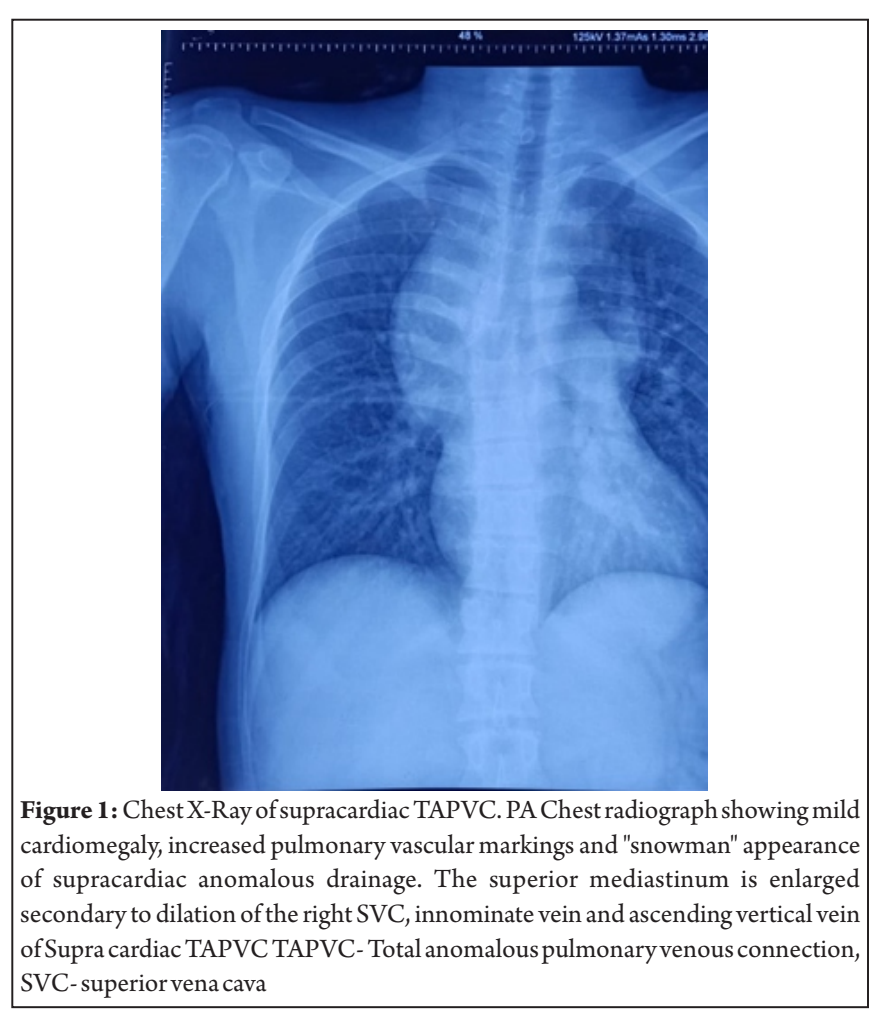

established a diagnosis of nonobstructive Supracardiac TAPVC and severe PAH (Fig. 2 A \& B). Following a confirmation of first and fifth day negative RTPCR reports and after obtaining the informed consent (including cross infection from COVID-19). The patient was posted for corrective cardiac repair under CPB.

The patient was premedicated with intramuscular morphine (0.1 $\mathrm{mg} / \mathrm{kg})$ and promethazine $(0.5 \mathrm{mg} / \mathrm{kg})$ one hour prior to surgery. The protocol for the cardiac surgery during the coronavirus disease 2019 pandemic for perioperative considerations and triage recommendations was strictly followed to reduce the risk of exposure to patients and healthcare workers. In the OR, routine American

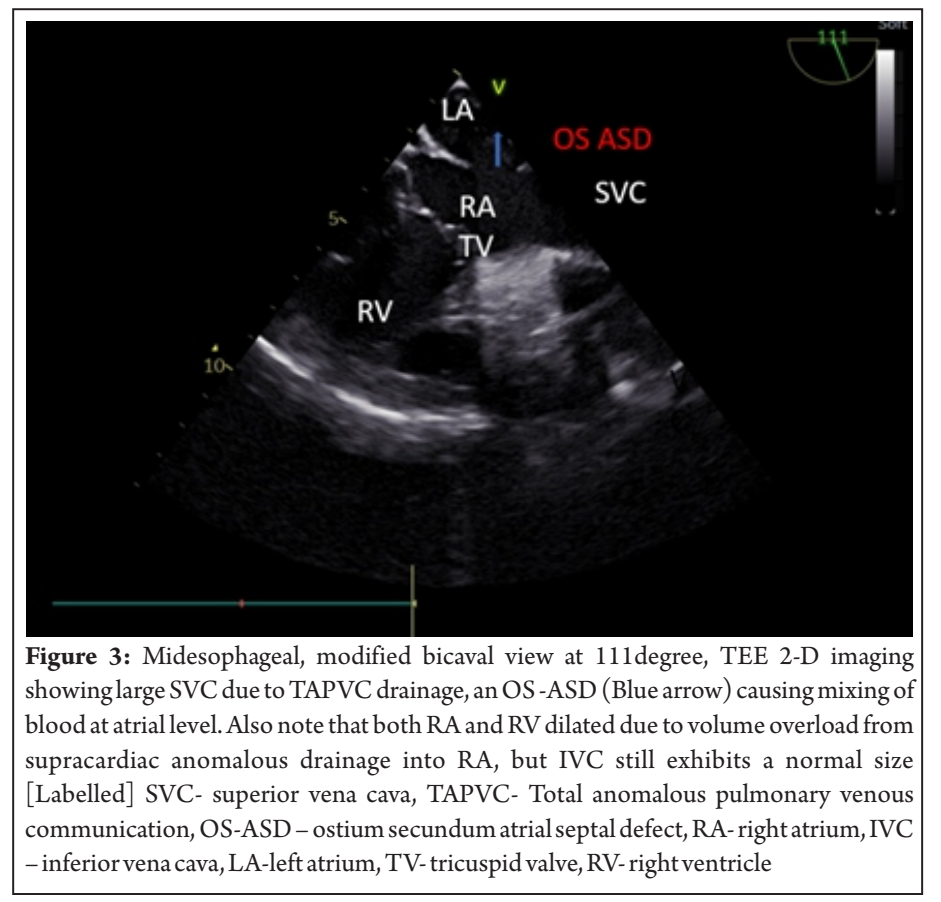

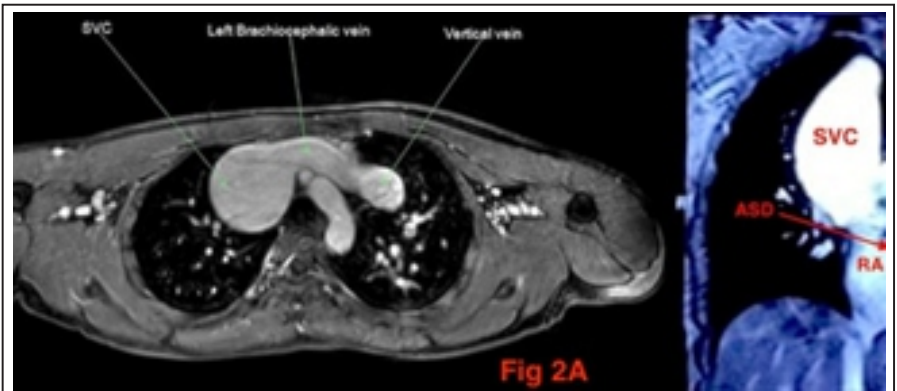

Figure 2: A \& B. Cardiac MRI imaging showing dilated common left vertical vein which drain into left innominate vein before draining into SVC and SVC is markedly dilated suggestive of supracardiac TAPVC as shown in Figure 2A. Figure 2 B depicts a nonobstructive TAPVC as a blood mixing occurring across the large OS- ASD with right to left shunt showing dilated SVC (Labeled). TAPVC- Total anomalous pulmonary venous connection, SVC-superior vena cava, OS-ASD- Ostium secundum atrial septal defect, $\mathrm{PV}$ - pulmonary vein, RA-right atrium

Society of Anaesthesiologists' monitors were adapted as per the severity of the disease and the invasiveness of the surgical procedure. His base line $\mathrm{SpO}_{2}$ was $92 \%$ on air. An intravenous access was achieved with $16 \mathrm{G}$, cannula to provide intravenous fluids and induction of anaesthesia. Cannulation of left radial artery with $22 \mathrm{G}$ catheter was performed under local anesthesia for continuous BP monitoring and intermittent arterial blood gas $(\mathrm{ABG})$ analysis. $\mathrm{ABG}$ analysis on room air revealed a $\mathrm{pH}$ of $7.36, \mathrm{PaCO}_{2} 34 \mathrm{~mm} \mathrm{Hg}, \mathrm{PaO}_{2} 64$ $\mathrm{mmHg}$, haemoglobin $19 \mathrm{~g}, \mathrm{HCO}_{3} 21 \mathrm{meq} / \mathrm{L}$, base Excess -1.2, ionized calcium $1.15 \mathrm{mg}$. Narcotic based balanced anesthesia was induced using fentanyl $(10 \mathrm{mcg} / \mathrm{kg})$, midazolam $(0.05 \mathrm{mg} / \mathrm{kg})$ and thiopentone $(60 \mathrm{mg})$, and rocuronium bromide $(50 \mathrm{mg})$ was used to facilitate endotracheal intubation with $9 \mathrm{~mm}$, cuffed tube, and nitrous oxide was omitted to avoid the further exaggeration of pre-existing PAH. 7- French gauge triple lumen central venous catheter was placed (under land mark technique) via right internal jugular vein to measure central venous pressure and for the administration of volume and

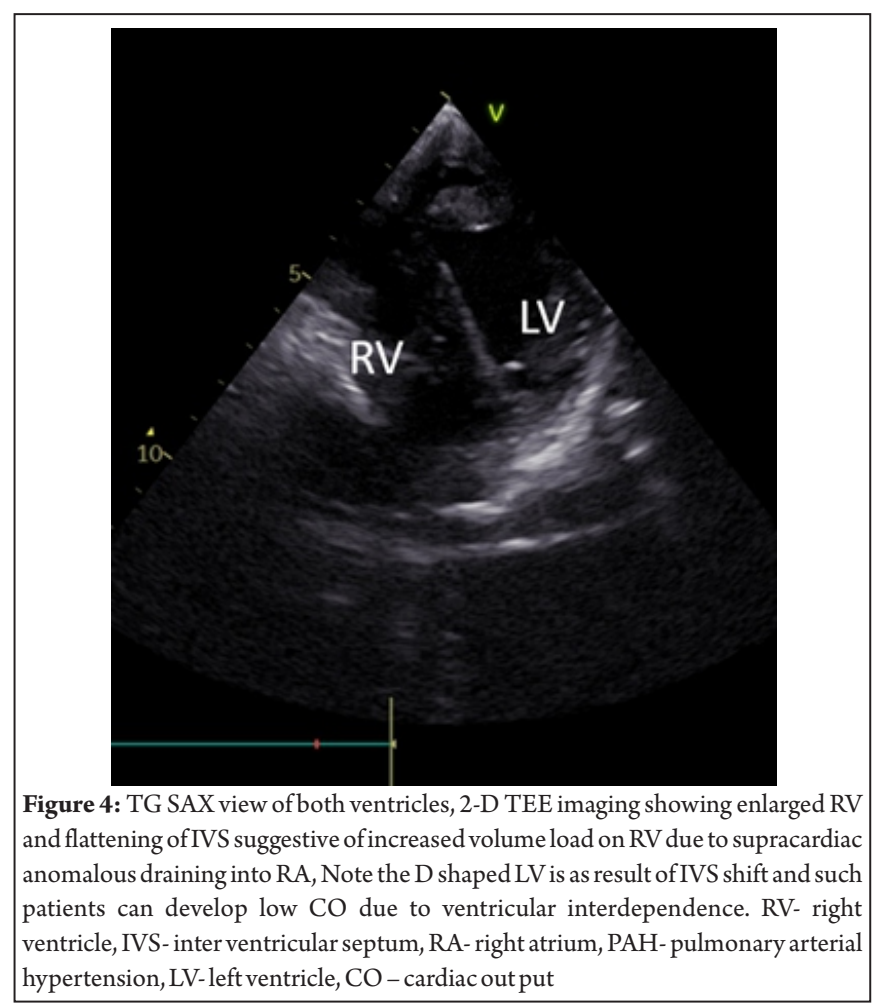


medication. His base line CVP was $6 \mathrm{mmHg}$, systemic BP was 112/78 $\mathrm{mmHg}$ and PAP was $72 / 50 \mathrm{mmHg}$ (systolic / mean) on direct needle insertion. Therefore, FiO2 of 1.0 and intravenous nitroglycerine [NTG] $(1.0 \mathrm{mcg} / \mathrm{kg} / \mathrm{min})$ were used to ameliorate the PAH. Anesthesia was maintained with intermittent use of fentanyl, midazolam, and sevoflurane (1-2 MAC). Intraoperative TEE was performed using a Pediatric TEE probe to avoid the obstruction of PVC, which also confirmed the diagnosis of unobstructed supracardiac TAPVC draining into SVC [size $3.4 \mathrm{~cm}$ ], OS-ASD with right to left shunt, enlarged RA and RV, RVSP of $56 \mathrm{~mm} \mathrm{Hg}$, moderate TR (vena contracta $0.5 \mathrm{~cm}$ ), RVEF of $45 \%$ and interventricular septum flattening (Fig. 3, 4) (Video 1 \& 2). LV functions were normal. Unfractionated Heparin sodium (300 units $/ \mathrm{kg}$ ) was used as an anticoagulant and after achieving an ACT value > 480 seconds, standard CPB technique with moderate hypothermia (27.5 degrees C) and antegrade blood cardioplegic (Del Nido) myocardial protection was used for corrective cardiac surgery. Per-operatively, the supracardiac TAPVC draining into the SVC and OS-ASD were identified by the operating surgeon (Fig. 5). After proper identification, the anastomosis of PVC to posterior wall of LA, ligation of vertical vein connecting to left innominate vein and closure of ASD with pericardium patch were performed. Weaning from CPB was easy with use of infusion of dobutamine $(2.5-5 \mathrm{mic} / \mathrm{kg} / \mathrm{min})$, milrinone $(0.5 \mathrm{mic} / \mathrm{kg} / \mathrm{min})$, and NTG $(1.0 \mathrm{mcg} / \mathrm{kg} / \mathrm{min})$. Immediately post $\mathrm{CPB}$; $\mathrm{SpO}_{2}$ was $100 \%$, mean arterial pressure (MAP) was $85 \mathrm{mmHg}$, mean LAP was $7 \mathrm{mmHg}$ and mean PAP was $10 \mathrm{mmHg}$ (measured by direct needle insertion). Total CPB time and aortic cross clamp time were $126 \mathrm{~min}$ and $97 \mathrm{~min}$ respectively and urine output was $1.5 \mathrm{~L}$. Post correction TEE confirmed; closure of ASD, pulmonary veins flow towards LA, (Video 3), IVS becoming more rounded towards RV and good biventricular functions. After heparin reversal with protamine, chest was closed, and patient was shifted to ICU for mechanical ventilation. Trachea was extubated after $8 \mathrm{hrs}$ and inodilators tapered

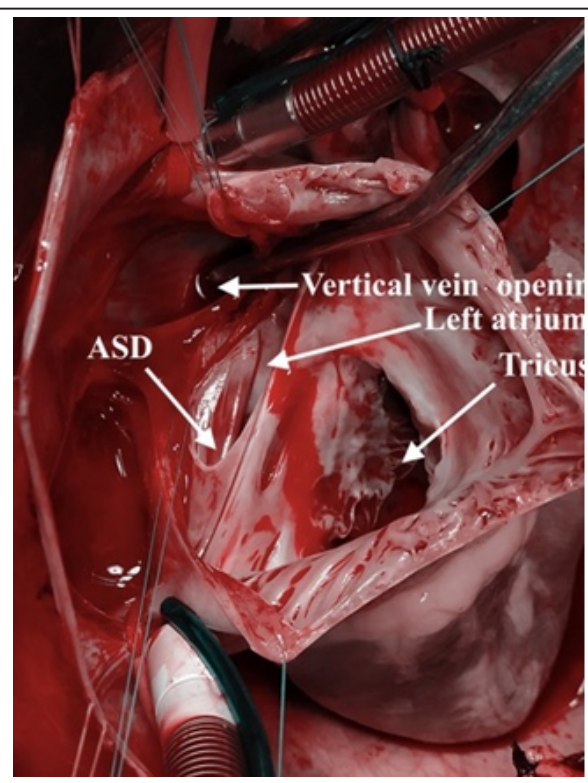

Figure 5: The intraoperative photograph showing the communication of vertical vein via innominate vein into the right SVC (labelled). in addition, there is an OS ASD providing mixing of blood at atrial level suggestive of unobstructed supra cardiac TAPVC SVC- superior vena cava, OS- ASD-atrial septal defect, TAPVC total anomalous pulmonary venous communication over the next 24 hrs. Patient was shifted to the stepdown unit on the $3^{\text {rd }}$ post-operative day and the further post-operative course was uneventful.

\section{Discussion}

TAPVC refers to a spectrum of congenital cardiac anomalies where the pulmonary veins fail to return to the LA and the oxygenated pulmonary venous blood returns through a systemic vein or directly to the right atrium or via coronary sinus and recirculate into the pulmonary circulation. So, it obligates a right to left atrial shunt to sustain the life $[6,7,8]$.It is a rare cardiac malformation with a reported incidence of around 7 per 100000 live births and accounts for $0.7-1.5 \%$ of all CHD $[6,7]$. TAPVC may be associated with a variety of comorbid cardiac defects like; Heterotaxy syndrome, VSD, Hypoplastic left heart syndrome, Double outlet right ventricle, Coarctation of the aorta, Truncus arteriosus and d-Transposition of the great arteries [7]. It has four main subtypes. The supracardiac type is seen in $45 \%$ of TAPVC patients; the PVC connects to a vertical vein that in turn connects to the innominate vein, and finally draining all pulmonary venous blood into the SVC and right atrium. The cardiac type of TAPVC (25\%) consists of the PVC draining into the coronary sinus or directly to the right atrium. The infracardiac type of TAPVC (20\%) consists of a PVC connected to a vertical vein that courses inferiorly through the oesophageal hiatus and below the diaphragm to join the portal vein or the ductus venosus or gastric or hepatic veins or directly to the inferior vena cava. Mixed types of TAPVC are rare and account for less than $10 \%$ of cases and is a combination of at least two subtypes [4]. Some authors have reported that more than $30 \%$ of cases of TAPVC present with pulmonary venous obstruction and obstruction is most common in neonates with infracardiac type and uncommon in cardiac type. So, a second consideration is whether the venous return is obstructed or a non-obstructed $[9,10]$.

Neonates with severe obstructive TAPVC present with marked

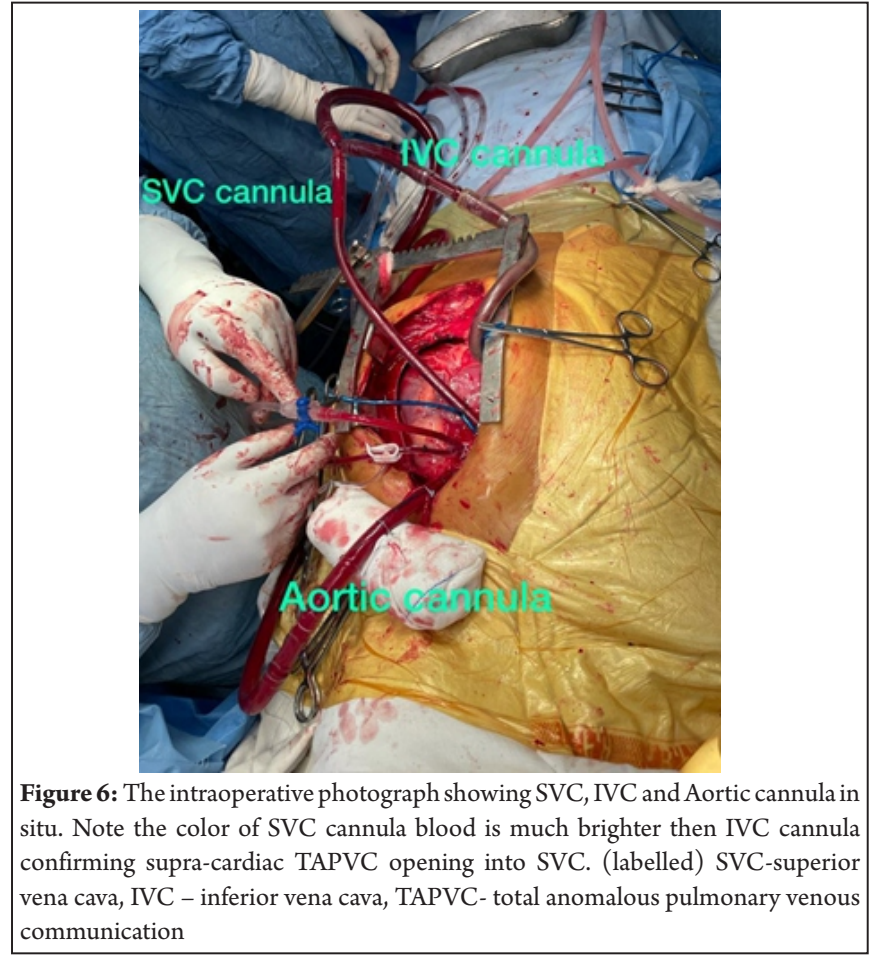


cyanosis, tachypnoea, dyspnoea, metabolic acidosis, low cardiac output, and vulnerable to death, and require an emergent intervention [11]. In addition neonates with obstructive TAPVC have a tendency to develop extraordinarily vulnerable $\mathrm{PAH}$ due to Pulmonary vascular changes in form of increased arterial medial thickness, intimal proliferation in preacinar veins, and abnormally small and thick-walled extrapulmonary veins [12]. Such babies often necessitate correction of metabolic acidosis with sodium bicarbonate, intubation and mechanically ventilation, and inotropic support prior to urgent surgical repair in an attempt to improve their oxygenation and cardiac output. However, there is little utility to prolonged preoperative stabilization of critically ill neonates as delayed surgery leads to worsening pulmonary edema and pulmonary hypertension [4]. No permanent catheter-corrective treatment is possible for TAPVC, although atrial septostomy is used in some patients when the foramen ovale is restricted and corrective surgery is delayed for some reason. Catheter placement of a stent has been reported for pre-treatment of obstructed vertical vein prior to surgery [13]. Preoperative ECMO is occasionally necessary in extreme cases with progressive hemodynamics and respiratory instability when surgery must be delayed in a critically ill patient. For the patients with persistent severe preoperative metabolic disorder, preoperative treatment with ECMO has been demonstrated to be effective in correcting and stabilizing viscera function, as well as improving outcomes of infants in critical conditions. Postoperative ECMO and inhaled nitric oxide (iNO) have been used significantly more in prenatally diagnosed, and pre and postoperative refractory $\mathrm{PAH}$ with RV failure and low cardiac output $[7,14]$.

Most of the neonates with unobstructed TAPVC present with milder cyanosis resulting from right to left shunting at atrial septum, and dyspnoea due to pulmonary over-circulation. The cyanosis is usually unresponsive to increased $\mathrm{FiO}_{2}$ and prostaglandin (PGE1) [4]. In the absence of pulmonary venous obstruction, the anomalous venous return imposes a volume load on the right heart resulting in right atrial and right ventricular dilation and also may develop RV failure [5]. Whereas a small number of patients with adequate blood mixing remain relatively asymptomatic and reach into adulthood $[7,15]$. Whereas, in a subset of patients the Increased pulmonary blood flow eventually leads to muscularization of the pulmonary vascular bed and may lead to $\mathrm{PAH}$. In such patients, the right ventricular pressure and volume overload can produce leftward displacement of the interventricular septum, and distortion of LV architecture and diminishes LV filling, and may exist with Low cardiac output after correction in patients with refractory $\mathrm{PAH}$. The presented patient also had RV and RA volume overload and flatten IVS [Fig. 4]. However, adequate cardiac correction and use of milrinone, dobutamine and NTG, lead to a significant improvement in PAH [MPAP-10 $\mathrm{mmHg}$ ], normalization of IVS position, and stable hemodynamics.

In the supracardiac TAPVC the pulmonary veins typically finally drain into the SVC as described earlier. Infrequently, the vertical vein may drain to the SVC or the azygous vein directly $[4,9]$. The patient, $s$ presentation, surgical repair, and outcomes depends upon the anatomical variability of venous connections, degree of pulmonary venous obstruction, severity of $\mathrm{PAH}$, mixing of blood and biventricular functions. If the pulmonary veins are unobstructed, some patients may remain asymptomatic at birth, about $50 \%$ will present in the first month with heart failure when PVR decreases, and the rest will present by the first year of life (most patients have heart failure by 6 months of life) $[16,17]$. The decrease in transatrial mixing not only increases the pulmonary over circulation but also diminishes the LV output. The mortality of untreated patients is $75-85 \%$ by 1 st year of life [18]. Husain et al. have reported that supracardiac TAPVC presents with obstruction in $23.1 \%$ as compare to $69.2 \%$ of infracardiac and $9.7 \%$ cardiac [19]. Some authors have reported an early surgical mortality of $9.8 \%$ and a late mortality of $3.9 \%$. and of all variables analysed in the series, TAPVC type and evidence of obstruction at time of repair have been noted to be associated with early surgical mortality. Whereas variables associated with late mortality include as heterotaxy syndrome, single ventricle physiology, additional surgical procedures, longer $\mathrm{CPB}$ times, and initial findings of pulmonary venous obstruction have all been found to be significant variables of association $[19,20]$. Others have suggested that the variables like preoperative pulmonary venous obstruction, ventilator $\mathrm{FiO}_{2}$, inotropic use, as well as postoperative pulmonary venous obstruction, low cardiac output, bleeding, ventilator $\mathrm{FiO}_{2}$, epinephrine use, restenosis and emergent repair as significant predictors of mortality in TAPVC [21]. White et al. have suggested that mixed-type TAPVC is an independent risk factor for postoperative obstruction, particularly in patients with isolated TAPVC. Even mild preoperative obstruction is a risk factor for postoperative obstruction [22].

The anatomy of the supracardiac TAPVC in our patient was typically similar as described earlier and mixing occurred at atrial level with right to left shunt and presented with symptoms of PAH in adulthood. (Fig. 4, 5), (Video 2, 3). In addition to the echocardiography and MRI findings, the brighter colour of blood seen in the superior vena-cava (SVC) cannula in comparison to that in the inferior venacava (IVC) cannula was suggestive of higher oxygen saturation in SVC. This too confirmed that the supra-cardiac TAPVC was draining into SVC in this patient (Fig. 6). However, PAPVC may be the other possibility of this brighter blood colour of SVC cannula.

The presentation of TAPVC is highly variable, and depends upon the type of TAPVC, presence or absence of obstruction, age of the patient, hemodynamic response to therapy, level of desaturation and biventricular functions, and component of $\mathrm{PAH}$. Accordingly, the anaesthetic and hemodynamic goals are also variable. So, here it is not possible to be prescriptive. In some patients primary aim is to prevent mortality (obstructed TAPVC with inadequate mixing of two circulations) with the use of inotropes, mechanical ventilation, atrial septostomy in cardiac catheterization laboratory, or ECMO support in extremes cases. whereas in other subset of patients the PAH and RV failure need proper management $(7,13,14)$. So, it is imperative to individualize the anaesthetic technique. These patients with right to left shunt are always susceptible to paradoxical air embolism and need a meticulous care to ensure that intravenous lines are completely free from air. A balanced anaesthetic technique consists of opioids, benzodiazepines and low-dose volatile anaesthetic agents is suitable for maintenance of anaesthesia. Nearly all inhalational anaesthetics' block ATP-dependent potassium channels whose activation induces vascular relaxation. Regardless of the specific anaesthetic technique, the hemodynamic goals are to maintain the cardiac output $(\mathrm{CO})$ and to minimize pulmonary edema and PAH. Perioperatively, continuous 
attention should be given to the oxygenation, ventilation, acidosis, volume status and anaesthetic depth to avoid further exacerbation of PVR, as the RV may also struggle to maintain cardiac output in the face of elevated pulmonary artery pressures $[4,23]$. After $\mathrm{CPB}$, these patients often require inodilators (milrinone $0.5 \mathrm{mcg} / \mathrm{kg} / \mathrm{min}$, dobutamine $5 \mathrm{mcg} / \mathrm{kg} / \mathrm{min}$, levosimendan $0.1 \mathrm{mcg} / \mathrm{kg} / \mathrm{min}$ ) in order to augment $\mathrm{CO}$, and $\mathrm{RV}$ and $\mathrm{LV}$ contractility, and to provide biventricular afterload (PVR, SVR) reduction [4]. Authors have also used NTG, dobutamine, milrinone, and $\mathrm{FiO}_{2}$ of 1.0, and avoided nitrous oxide to ameliorate the $\mathrm{PAH}$ and augment cardiac contractility and $\mathrm{CO}$.

In addition to the standard ASA monitoring, invasive arterial pressure, CVP and TEE monitoring has been recommended. If TEE is used, it should be done cautiously as the probe in the mid-oesophageal position lies directly behind the PVC and can cause life-threatening pulmonary venous obstruction in supra cardiac TAPVC, and so, some authors have suggested the use of a microsized TEE probe to mitigate this hemodynamic effect [4]. Following the same considerations (to avoid the PVC compression), even in this patient the paediatric size TEE probe was utilized to guide the fluid and drug therapy as well as the assessment of ventricular functions, surgical correction and for early diagnosis RV decompensation. PVR can also be measured by TEE using TRV $(\mathrm{m} / \mathrm{s})$ and VTIRVOT $(\mathrm{cm})$. [PVR (Wood units) $=10 \times($ TRV/VTIRVOT) +0.16 . (TRV, VTIRVOT; time-velocity integral of Tricuspid Valve and RVOT flow). Here, a TRV/VTI RVOT $<0.2$ corresponds approximately to a PVR of $<2$ Wood units [24]. Correction of TAPVC may impose an acute volume load on the LV, which may be noncompliant and prone to over distension with excessive fluid administration and require accurate assessment by TEE.

Regardless of the anaesthesia technique the care providers should strictly follow the protocol described by Patel et al. for the cardiac surgery during the COVID-19 pandemic for perioperative considerations and triage recommendations to reduce the risk of exposure to patients and healthcare workers and allocate resources appropriately to those in greatest need [25]. The cardiac surgical patients are a unique population in this COVID-19 epidemic because cardiac surgery comes under very high risk of exposure to COVID-19 infection from droplet dispersion and transmission from others. During cardiothoracic surgery, various aerosol-generating procedures (AGPs) include intubation, extubation, tracheostomy, bronchoscopy, endoscopy, laparoscopy, any cardiac or thoracic surgery, chest tube placement, and Bovie cautery use. These patients are also potential for prolonged hospitalization or ICU stay, and the overall intense healthcare resource use. In addition, knowing a patient's preoperative COVID-19 status may help with postoperative management and counselling as recent evidence suggests that asymptomatic COVID-19 patients who undergo surgery may be more susceptible to pneumonia and ARDS postoperatively [25].

Although the PAH in our patient was well under control after administration of nitroglycerine, dobutamine and milrinone, some patients with pre-existing $\mathrm{PAH}$ may develop critical pulmonary hypertensive crisis (PHC) after CPB. Several mechanisms have been hypothesized for PHC following CPB; micro emboli, complement activation, and pulmonary leuko-sequestration during $\mathrm{CPB}$, mechanical failure, pulmonary reperfusion syndrome, altered pulmonary endothelial function following $\mathrm{CPB}$, and existing preoperative $\mathrm{PAH}$ may persist postoperatively, and even blood transfusions may exacerbate PAH. Whereas hypoxia, hypercarbia, and pulmonary embolism are other causes of $\mathrm{PAH}$, and these can appear before, during, or after CPB [26, 27, 28]. The PHC has been reported to be associated with significant mortality. Mubeen et al. have reported an operative mortality of $28.5 \%$ in patients with supra systemic PAP or high PVR [29]. Therefore, in patients with nearly or supra systemic $\mathrm{PAH}$ assessment of reversibility of pulmonary hypertension (with the use of $100 \%$ Oxygen, or NTG or iNO) is mandatory to determine intraoperative course and outcome [30]. A baseline preoperative pulmonary vascular resistance index (PVRI) of $<6 \mathrm{WU} / \mathrm{m}^{2}$ and a pulmonary to systemic vascular resistance ratio $<0.3$ have been suggested as a favorable outcome indicator and patients can be subjected to cardiac surgery without undergoing inhaled $\mathrm{NO}$ or $\mathrm{O}_{2}$ challenge. Conversely, the vasoreactivity challenge is encouraged to assess the hemodynamic changes for operability in patients with $\mathrm{PAH}$ associated with CHD; if baseline PVR between 6 and $9 \mathrm{WU} / \mathrm{m}^{2}$, the PVR: SVR ratio 0.3-0.5, and the post challenge decrease in PVR index 20\%, PVR: SVR decreases by 20\%, final PVR index <0.3, Qp/Qs $>1.5: 1$, and basal saturations not $<95 \%$ determine the operative suitability [31]. PH is also considered responsive when PAPm decreases by at least $10 \mathrm{mmHg}$ or PAPm decreases to an absolute value of $40 \mathrm{mmHg}$ or CO increases [32].

It is not possible to provide the detailed management of $\mathrm{PHC}$ here, but care providers should focus on avoiding the precipitating factors as described above, optimise the RV preload with the titrated volume or diuretics (frusemide), improve the RV contractility with the use of inodilators and inotropes (milrinone, dobutamine, levosimendan (0.1 $\mathrm{mcg} / \mathrm{kg} / \mathrm{min}$ ), epinephrine etc). Modified ultrafiltration (MUF) after separation from $\mathrm{CPB}$ reduces biochemical mediators involved in pulmonary vasoconstriction and may reduce the risk of pulmonary hypertension as well as the duration of mechanical ventilation and decreases post CPB morbidity in pediatric cardiac surgery [26, 29, 33]. Reactive component of PAH usually comes down after operation. In refractory cases, selective pulmonary vasodilators are used to decrease the RV afterload and to avoid the systemic hypotension like, intravenous sildenafil ( $0.4 \mathrm{mg} / \mathrm{kg}$ over $3 \mathrm{hrs}$ followed by an infusion of $0.07 \mathrm{mg} / \mathrm{kg} / \mathrm{hr}$ ), inhaled prostaglandins [epoprestenol(10-50 $\mathrm{ng} / \mathrm{kg} / \mathrm{min}$ ), iloprost (25 mcg over $10 \mathrm{~min}$ ), treprostinil(50-80 $\mathrm{ng} / \mathrm{kg} / \mathrm{min})$ ], iNTG(2.5 mcg/ kg/min), iSNP(total dose of $25 \mathrm{mg}$ ), iMilrinone $(50-80 \mathrm{mcg} / \mathrm{kg} / \mathrm{min})$, and iNO (10-50 ppm). Usage of a combination of all vasodilators as mentioned above can cause a severe vasodilation and even vasoplegic syndrome. Therefore, it is suggested that use one drug at a time like Milrinone or Dobutamine and see the response if PA pressures are still high NTG or other selective or

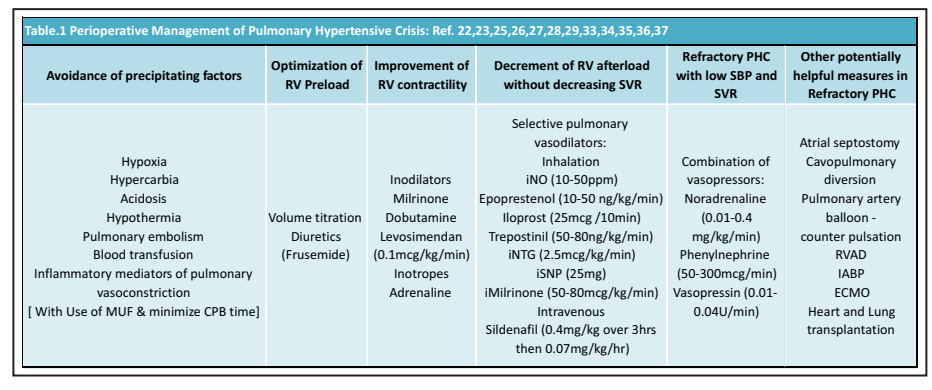


inhalational pulmonary vasodilators can be added. $\mathrm{PHC}$ patients with low systolic blood pressure and low SVR may require concomitantly a single or combination of vasopressors and lot of fluids [norepinephrine (0.01-0.4 mg/kg/min), phenylephrine, (50-300 $\mu \mathrm{g} / \mathrm{min})$, vasopressin $(0.01-0.04 \mathrm{U} / \mathrm{min})$, methylene blue (1$2 \mathrm{mg} / \mathrm{kg}$ ) hydroxocobalamin ( $5 \mathrm{~g}$ bolus)] to maintain MAP and coronary perfusion $[34,35,36,37,38]$. The AHA/ATS PH guidelines recommend inhaled nitric oxide (iNO) as a first-line agent in treating and preventing perioperative PHC. It improves ventilation/perfusion matching, decreases the intrapulmonary shunt fraction, and often increases the systemic arterial saturation [39]. If the above measures fail in improving the clinical status then other options may be considered, such as atrial septostomy, Cavo-pulmonary diversion, pulmonary artery balloon counter pulsations, IABP, RVAD, ECMO, and in desperate situation, if facilities exist then plan for heart and lung transplant $[26,40,41,42]$ (Table 1$)$.

\section{Conclusion}

Patients with unobstructed supracardiac TAPVC with adequate mixing at atrial level with right to left shunt can present with mild cyanosis and reach the adult hood with development of significant PAH. Such patients can be successfully managed for cardiac correction by employing an individualised balanced anaesthesia technique, and under standard ASA monitoring along with use of pediatric size TEE probe. Use of nitroglycerine, milrinone, dobutamine infusions and avoidance of nitrous oxide can help to ameliorate postoperative PAH. Regardless of the anaesthetic technique, the protocol for the cardiac surgery during the COVID-19 pandemic for perioperative considerations and triage recommendations should be strictly followed to reduce the risk of exposure to patients and healthcare workers and allocate resources appropriately to those in greatest need, as cardiac surgery comes under extremely high risk of exposure to COVID-19 infection from droplet dispersion and transmission from others [25].

Declaration of patient consent: The authors certify that they have obtained all appropriate patient consent forms. In the form, the patient has given his consent for his images and other clinical information to be reported in the Journal. The patient understands that his name and initials will not be published, and due efforts will be made to conceal his identity, but anonymity cannot be guaranteed.

\section{Conflict of interest: Nil Source of support: None}

\section{References}

1. Herlong JR, Jaggers JJ, Ungerleider RM. Congenital Heart Surgery Nomenclature and Database Project: pulmonary venous anomalies. Ann Thorac Surg. 2000;69(suppl): S56-S69.

2. Reller MD, Strickland MJ, Riehle-Colarusso T, et al. Prevalence of congenital heart defects in metropolitan Atlanta, 1998-2005.J Pediatr $2008 ; 153: 807$.

3. Hoffman JI, Kaplan S. The incidence of congenital heart disease. J Am Coll Cardiol 2002; 39:1890.

4. Ross FJ, Joffe D, Latham GJ. Perioperative and Anesthetic Considerations in Total Anomalous Pulmonary Venous Connection. Semin Cardiothorac Vasc Anesth. 2017;21(2):138-144

5. Hines MH, Hammon JW. Anatomy of total anomalous pulmonary venous connection. Oper Tech Thorac Cardiovasc Surg. 2001; 6:2-7.

6. Seale AN, Uemura H, Webber SA, et al. Total anomalous pulmonary venous connection: morphology and outcome from an international population-based study. Circulation. 2010; 122:2718-2726

7.Domadia S, Ram Kumar S, Smith JKV, PruetzJD. Neonatal Outcomes in Total Anomalous Pulmonary Venous Return: The Role of Prenatal Diagnosis and Pulmonary Venous Obstruction. Pediatric Cardiology. $2018 ; 39: 1346-1354$.

8. Files MD, Morra B. Total Anomalous Pulmonary Venous Connection: Preoperative Anatomy, Physiology, Imaging, and Interventional Management of Postoperative Pulmonary Venous Obstruction. Semin Cardiothorac Vasc Anesth. 2017; 21(2):123-131

9. Padalino MA, Cavalli G, De Franceschi M, et al. Surgical outcomes of total anomalous pulmonary venous connection repair: a 22 -year experience. J Card Surg. 2014; 29:678-685.

10. Hancock Friesen CL, Zurakowski D, Thiagarajan RR, et al. Total anomalous pulmonary venous connection: an analysis of current management strategies in a single institution. Ann Thorac Surg. 2005; 79:596-606

11. Munsi AS, Hussain M, Rima R, Biswas R, Sayeed A. Clinical profile of patients with Total Anomalous Pulmonary Venous Return and their short-term outcome in pediatric cardiac centre at Dhaka Shishu Hospital Bangla J of Med Scie.2015 JULY Vol. 14 No. 03:270-273

12. Haworth SG. Total anomalous pulmonary venous return. Prenatal damage to pulmonary vascular bed and extrapulmonary veins. $\mathrm{Br}$ Heart J. 1982; 48:513-524.

13. Kyser JP, Bengur AR, Siwik ES. Preoperative palliation of newborn obstructed total anomalous pulmonary venous connection by endovascular stent placement. Cathter Cardiovasc Intev. 2006; $67(3): 473-6$

14. Konstantinov IE. Primary sutureless repair of total anomalous pulmonary venous connection: the value of intrapleural hilar reapproximation. Journal of Thoracic and Cardiovascular Surgery.2006; 132(3):729-730

15. Kong D, Pan C, Dong L, Jin H, Shu X. Rare variant of mixed total anomalous pulmonary venous drainage (TAPVD) in a 55-year-old patient. Eur Heart J Cardiovasc Imaging. 2015; 16:227

16. Fred M. Wu, Sitaram M. Emani, Michael J. Landzberg, and Anne Marie Valente, Rare Case of Undiagnosed Supracardiac Total Anomalous Pulmonary Venous Return in an Adult. Circulation.2014; 130, 12051207

17. Qasim A .Supracardiac Total Anomalous Pulmonary Venous Return. Pediatric echocardiography: online instructions $n$ interpretive echocardiography for improved detection of congenital heart disease in clinical settings 
18. Gökmen Akkaya 1 • Çağatay Bilen 2 • Osman Nuri Tuncer 3 • Mehmet Fatih Ayık 3 - Yüksel Atay. Evaluation of Surgical Treatment in Patients with Total Anomalous Pulmonary Venous Connection. EJCM 2018;6(3):107-112

19. S. Adil Husain, MD, Elaine Maldonado, MD, Debbie Rasch, MD, Joel Michalek, MD, Richard Taylor, MD et al. Total Anomalous Pulmonary Venous Connection: Factors Associated with Mortality and Recurrent Pulmonary Venous Obstruction. Ann Thorac Surg 2012; 94:825-32

20. Karamlou T, Gurofsky R, Al Sukhni E, Coles JG, Williams WG, et al. Factors associated with mortality and reoperation in 377 children with total anomalous pulmonary venous connection. Circulation. 2007;115(12):1591-1598

21. Wu CL, Kan CD, Wu JM, Wang JN. Risk Factors of Total Anomalous Pulmonary Venous Connection Surgery. Pediatrics \& Health Research 2016;1(3):1-6

22. White BR, Ho DY, Faerber JA, Katcoff H, Glatz AC, Mascio CE et al.Repair of Total Anomalous Pulmonary Venous Connection: Risk Factors for Postoperative Obstruction. Ann Thorac Surg . 2019 ;108(1):122-129.

23. Cheng JW, Tonelli AR, Patterson G, and Krasushki RA et al, Pharmacologic Management of Perioperative Pulmonary Hypertension.J Cardiovasc Pharmacol. 2014; 63(4):375-384

24. Abbas AE, Fortuin FD, Schiller NB, Appleton CP, Moreno CA et al. A simple method for noninvasive estimation of pulmonary vascular resistance. Journal of the American College of Cardiology 2003. 41 1021-1027

25. Patel V, Jimenez E, Cornwell L, Tran T, Paniagua D et al. Cardiac Surgery During the Coronavirus Disease 2019 Pandemic: Perioperative Considerations and Triage Recommendations. J Am Heart Assoc. 2020;9: e017042

26. Datt V, Khurana P, Aggarwal S, Mishra S , Sujith CN, and Virmani S. Perioperative Management of a Patient with Double Orifice Mitral Valve with Supramitral Ring with Subaortic Membrane with Ventricular Septal Defect and Severe Pulmonary Hypertension: Report of a Rare Case. Ann Card Anaesth. 2019; 22(2):215-220

27. Kaestner M, Schranz D, Warnecke G, Apitz C, Hansmann G et al. Pulmonary hypertension in the intensive care unit. Expert consensus statement on the diagnosis and treatment of paediatric pulmonary hypertension. European Paediatric Pulmonary Vascular Disease. Network endorsed by ISHLT and DGPK. Heart. 2016; 102: ii57-ii66.

28. Taylor MB, Laussen PC. Fundamentals of management of acute postoperative pulmonary hypertension. Pediatr Crit Care Med. 2010;11:S27-S29.

29. Mubeen M, Singh AK, Agarwal SK, Pillai J, Kapoor S, et al. Mitral valve replacement in severe pulmonary arterial hypertension. Asian Cardiovasc Thorac Ann. 2008; 16:37-42.

30. Coutinho GF, Antunes MJ. Surgery for mitral stenosis in patients with pulmonary hypertension: How far can we go?. J Thorac Cardiovasc Surg 2016;152:302-3

31. Myers PO, Tissot C, Beghetti M. Assessment of operability of patients with pulmonary arterial hypertension associated with congenital heart disease - Do we have the good tools to predict success? Circ J 2014;78:4-11

32. Simonneau G, Gatzoulis MA, Adatia I, Celermajer D, Denton C et al. Updated clinical classification of pulmonary hypertension. J Am Coll Cardiol.2013;62:D34-41]

33. Ziyaeifard M, Alizadehasl A, Massoumi G. Modified Ultrafiltration During Cardiopulmonary Bypass and Postoperative Course of Pediatric Cardiac Surgery. Res Cardiovasc Med. 2014; 3(2): e17830.

34. Onoe M, Oku H, Kitayama H, Matsumoto T, Kaneda T. Modified ultrafiltration may improve postoperative pulmonary function in children with a ventricular septal defect. Surg Today. 2001;31(7):586-90

35. Condliffe R, Kiely DG. Critical care management of pulmonary hypertension. BJAEducation 2017; 17 (7):228-234

36. Thunberg CA, Morozowich ST, Ramakrishna H. Inhaled therapy for the management of perioperative pulmonary hypertension. Ann Card Anaesth. 2015; 18(3):394-402

37. Sarkar MS, Desai PM. Pulmonary Hypertension and Cardiac Anesthesia: Anesthesiologist's perspective. Ann card anesth, 2018; 21(2): 116-122

38. Burnes ML, Boettcher BT, Woehlck HJ, Zundel MT, Iqbal Z et al. Hydroxocobalamin as a Rescue Treatment for Refractory Vasoplegic Syndrome After Prolonged Cardiopulmonary Bypass. J Cardiothorac Vasc Anesth.2017;31(3): 1012-1014

39. Abman SH, Hansmann G, Archer SL, et al. Pediatric Pulmonary Hypertension: Guidelines From the American Heart Association and American Thoracic Society. Circulation. 2015; 132(21):2037-2099

40. Denault A, Deschamps A, Tardif JC, Lambert J, Perrault L. Pulmonary hypertension in cardiac surgery. Curr Cardiol Rev. 2010; 6:1-4.

41. Kameny RJ, Fineman J, Adatia I. Perioperative Management of Pediatric Pulmonary Hypertension. Adv Pulmonary Hypertens. 2016; 15:87-91

42. Gorter TM, Verschuuren EAM, Veldhuisen DJ, Elke S Hoendermis ES et al. Right ventricular recovery after bilateral lung transplantation for pulmonary arterial hypertension. Interact Cardiovasc Thorac Surg. 2017;24(6):890-897

How to Cite this Article

Datt V, Wadhwa R, Kumar M, Sharma V, Chaudhary R, Virmani S | Perioperative Anesthetic Management for Surgical Repair of an Adult with Supracardiac Total Anomalous Pulmonary Venous Communication and Pulmonary Hypertension- Case Report and Mini Review | Journal of Anaesthesia and Critical Care Case Reports | September-December 2021; 7(2): 10-16. 